Subscriber access provided by Caltech Library

\title{
Article
}

\section{Mechanistic Studies on Selective Trimerization of Linear Alpha Olefins over a Supported Titanium Catalyst}

D. Keith Steelman, Dinesh C. Aluthge, Matthew C. Lehman, Jay A. Labinger, and John E. Bercaw ACS Catal., Just Accepted Manuscript • DOI: 10.1021/acscatal.7b00256 • Publication Date (Web): 14 Jun 2017

Downloaded from http://pubs.acs.org on June 16, 2017

\section{Just Accepted}

"Just Accepted" manuscripts have been peer-reviewed and accepted for publication. They are posted online prior to technical editing, formatting for publication and author proofing. The American Chemical Society provides "Just Accepted" as a free service to the research community to expedite the dissemination of scientific material as soon as possible after acceptance. "Just Accepted" manuscripts appear in full in PDF format accompanied by an HTML abstract. "Just Accepted" manuscripts have been fully peer reviewed, but should not be considered the official version of record. They are accessible to all readers and citable by the Digital Object Identifier (DOI®). "Just Accepted" is an optional service offered to authors. Therefore, the "Just Accepted" Web site may not include all articles that will be published in the journal. After a manuscript is technically edited and formatted, it will be removed from the "Just Accepted" Web site and published as an ASAP article. Note that technical editing may introduce minor changes to the manuscript text and/or graphics which could affect content, and all legal disclaimers and ethical guidelines that apply to the journal pertain. ACS cannot be held responsible for errors or consequences arising from the use of information contained in these "Just Accepted" manuscripts. 

Olefins over a Supported Titanium Catalyst

\author{
D. Keith Steelman, Dinesh C. Aluthge, Matthew C. Lehman, Jay A. Labinger* and \\ John E. Bercaw* \\ Arnold and Mabel Beckman Laboratories of Chemical Synthesis, California Institute \\ of Technology, Pasadena, California 91125, USA
}

\begin{abstract}
The supported titanium catalyst $\mathrm{s}(\mathrm{FI}) \mathrm{Ti}$, generated by adding $(\mathrm{FI}) \mathrm{TiCl}_{3}$ to $\mathrm{MAO}$-treated $\mathrm{SiO}_{2}$ (FI = (N-(5-methyl-3-(1-adamantyl)salicylidene)-2'-(2'--methoxyphenyl)anilinato)], effects the selective trimerization of the linear $\alpha$-olefins (LAOs) propene, 1-pentene, 1 hexene, 1 -decene, with $>95 \%$ selectivity for trimers and $\sim 85 \%$ selectivity to a single isomer thereof (2,3,5-trialkyl-1-hexene). Mechanistic interpretations are offered for the high regioselectivity as well as for some unusual kinetics behavior, including third-order dependence on LAO concentration and nearly identical initial rates at 0 and $25^{\circ} \mathrm{C}$.
\end{abstract}

\title{
KEYWORDS
}

selective olefin trimerization, supported catalyst, titanium, metallacyclic mechanism, kinetics

\section{INTRODUCTION}

The selective oligomerization of linear $\alpha$-olefins (LAOs) is a potentially valuable route to higher value products, such as diesel and/or jet fuel, ${ }^{1}$ lubricants, ${ }^{2}$ and precursors to surfactants and detergents. Whereas there are a number of selective ethylene trimerization catalysts, ${ }^{3}$ only two catalysts have been reported to be effective for selective LAO trimerization. $\left(\mathrm{R}_{3} \mathrm{TAC}\right) \mathrm{CrCl}_{3}\left(\mathrm{R}_{3} \mathrm{TAC}=\right.$ trialkyltriazacyclohexane $)$ converts LAOs to isomeric mixtures of olefin trimers upon activation by excess MAO (100 eq). ${ }^{4}$ More recently, we have found that two modified versions of the so-called Fujita catalyst $\left((\mathrm{FI}) \mathrm{TiCl}_{3}\right.$, where $\mathrm{FI}=(N$-(5-methyl-3-(1-adamantyl)salicylidene $)-2$ ' $-(2$ 'methoxyphenyl)anilinato)], activated by 10,000 eq of $\mathrm{MAO}^{5}$ ) catalyze selective LAO trimerization (the original Fujita system does not). One of these is a soluble, stoichiometrically activated catalyst obtained from the reaction of (FI) $\mathrm{TiMe}_{3}$ with one equivalent of $\mathrm{B}\left(\mathrm{C}_{6} \mathrm{~F}_{5}\right)_{3} ;{ }^{6}$ the other is the supported catalyst $\mathrm{s}(\mathrm{FI}) \mathrm{Ti}$, generated by adding (FI) $\mathrm{TiCl}_{3}$ to MAO-treated $\mathrm{SiO}_{2}{ }^{7}$ In both cases LAOs (1-pentene, 1-hexene, 1-decene) are oligomerized with high $(>95 \%)$ selectivity for trimers and strong preference $(\sim 85 \%)$ for a single isomer thereof (Scheme 1). The supported catalyst exhibits higher productivity (as it does for ethylene trimerization), giving turnover numbers (TON) as high as $10^{3}-10^{4}$, a consequence of a slower rate of decomposition. ${ }^{6}$ While these results 
are encouraging, the levels of productivity obtained to date are probably too low for practical application. In the course of mechanistic studies, whose ultimate goal is to identify and improve the factors responsible for limiting productivity, we observed some unusual behavior with regard to temperature and concentration effects on reactivity, which we report upon here.

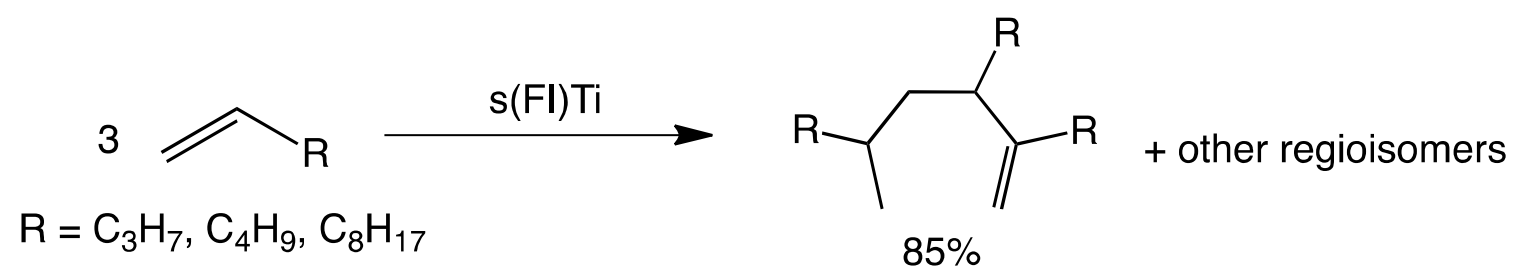

Scheme 1. Selective trimerization of LAOs.

\section{RESULTS}

The supported catalyst s(FI)Ti was prepared as reported previously. ${ }^{7}$ Stirring a suspension of s(FI)Ti in neat LAO (usually $100 \mathrm{mg}$ of catalyst containing $43 \mathrm{mmol} \mathrm{Ti} / \mathrm{g}$ with $2 \mathrm{~mL}$ LAO) under inert atmosphere at room temperature resulted in gradual consumption of monomer and formation of trimer over a period of 1-2 days, after which no further activity is observed. Diluting the LAO in an inert solvent (such as the corresponding alkane) gave considerably less efficient trimerization (see below). A typical reaction profile (for 1-decene) is shown in Fig. 1; 1-pentene and 1-hexene behaved similarly. In addition to trimers, substantial amounts of internal olefin isomers were generated, along with much smaller amounts of dimers; no heavier oligomers could be detected by GC, but removal of all volatile products under vacuum left a small residue, presumably consisting of heavy oligomers. We were unable to detect any measurable oligomerization of internal olefins, nor of branched terminal olefins such as 4-methyl-1-pentene. For example, reaction of $20 \mathrm{~mol} \%$ cis-3-hexene in 1-pentene gave only $\mathrm{C}_{15}$ products; no measurable incorporation or isomerization of the cis-3-hexene was detected. Unconjugated terminal-internal dienes such as 1,4-hexadiene are completely unreactive, whereas 1,3-butadiene undergoes rapid polymerization with no detectable trimer formation.

All three liquid LAOs exhibited $>90 \%$ selectivity to trimer (counting only volatile products) and $85-90 \%$ regioselectivity to the isomer shown in Scheme 1 above, with the same minor isomers observed previously. ${ }^{6,7}$ Productivity as high as $10^{3}-10^{4}$ turnovers (corresponding to trimer yields of $30-40 \%$, based on starting LAO) could be consistently obtained only when the LAO was carefully purified, including passage through a column of $\mathrm{MAO} / \mathrm{SiO}_{2}$ (i.e., the catalyst support without Ti), before use. The high sensitivity to air and water (and perhaps other impurities as well) of s(FI)Ti has been noted in previous studies. ${ }^{7,8}$ 


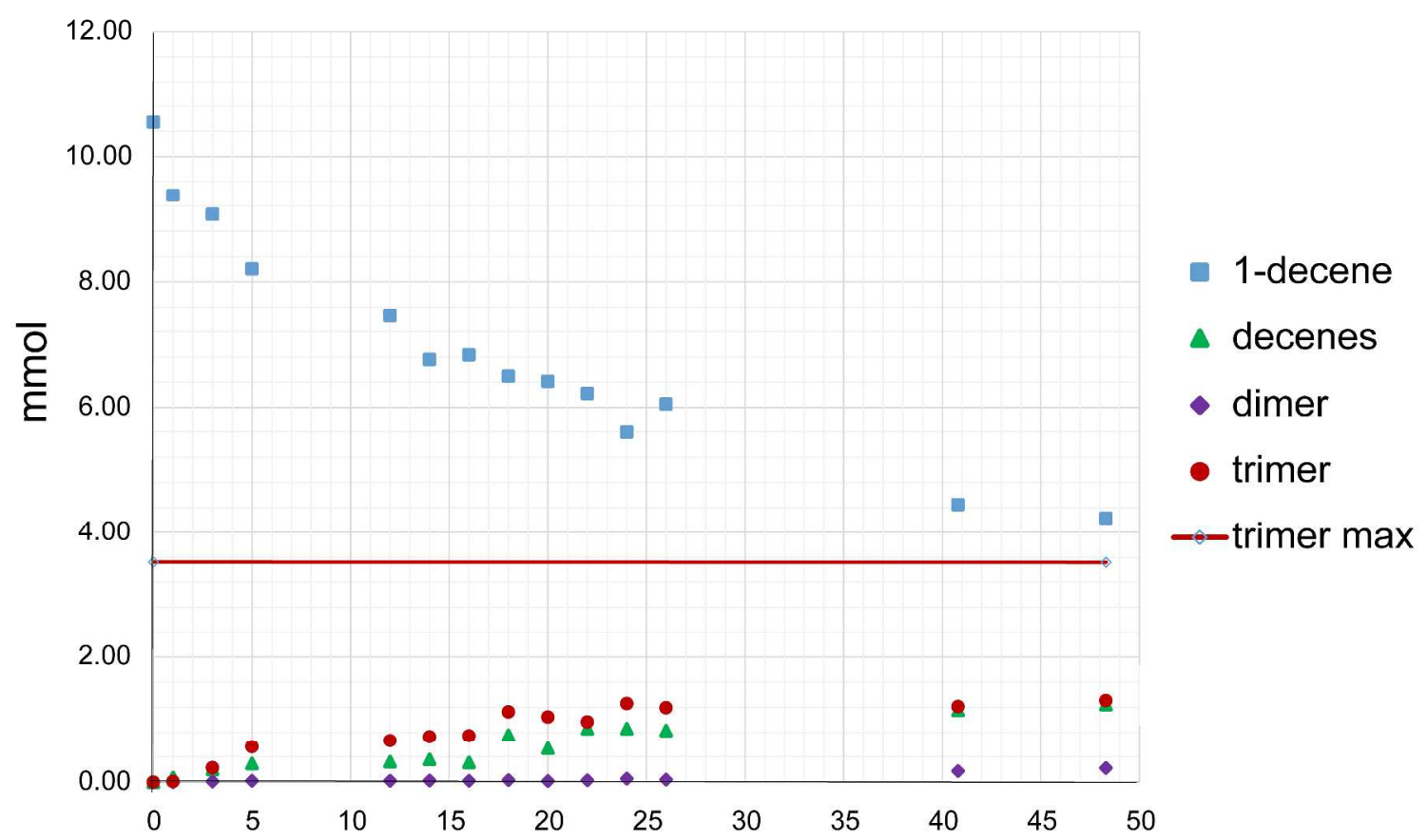

Figure 1. Consumption of 1-decene, and appearance of decene isomers, dimers and trimers, during catalysis by $\mathrm{s}(\mathrm{FI}) \mathrm{Ti}$ at $25^{\circ} \mathrm{C}$. The solid red line shows the theoretical maximum of trimer formation.

Propylene is also trimerized by s(FI)Ti. Rates are so slow when carried out in toluene or hexane slurry under $1 \mathrm{~atm}$ of propylene that the nonene product is barely detectable, but when carried out in liquid propylene under pressure at $9 \pm 3{ }^{\circ} \mathrm{C}$ for 2 days the reaction leads to 2,3,5-trimethyl-1-hexene with $88 \%$ selectivity $(43,000 \mathrm{TON})$. The somewhat higher TON for propylene, as compared with higher alpha olefins, may be attributable to its lower steric interactions with the catalyst site, as well as the fact that it can undergo only degenerate isomerization.

In light of the observed catalyst instability, we examined its behavior as a function of temperature from $0-50{ }^{\circ} \mathrm{C}$. Qualitatively, activity is observed over the entire range, with decomposition becoming more rapid at the higher temperatures. More quantitative studies at $0{ }^{\circ} \mathrm{C}$ (Fig. 2) reveal several significant features compared to room temperature: 1) decomposition is slower, with considerable activity remaining even after two days; 2 ) overall productivity is greater, by a factor of two or more; 3 ) isomerization is very much slower; and 4) surprisingly, the initial rate of trimer formation appears to be virtually the same. 
C18

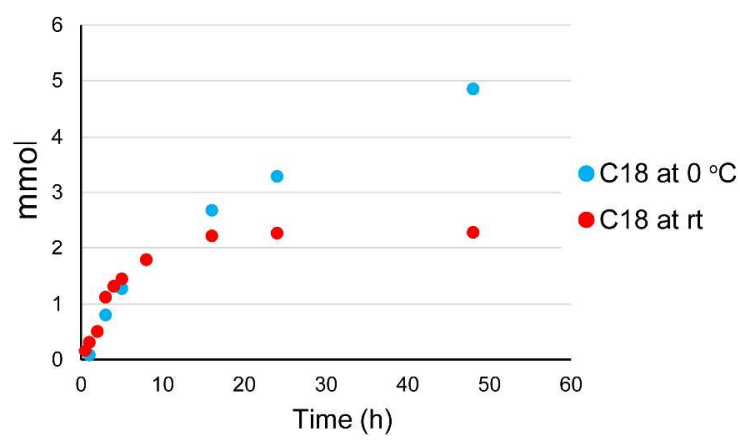

C6 isomers

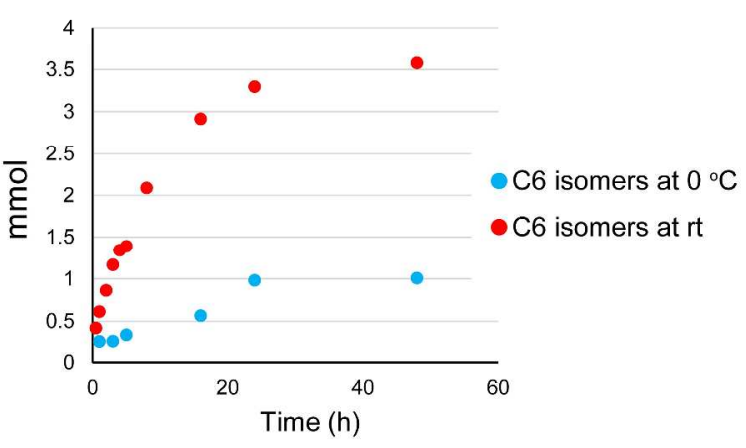

Figure 2. Catalytic trimerization of 1-hexene at 0 and $25^{\circ} \mathrm{C}$. (left) Formation of hexene trimers; (right) formation of internal hexene isomers.

As noted above, trimerization is considerably slower when the LAO is diluted, suggesting that the dependence of rate on [LAO] might be higher than first-order; ethylene trimerization by the original Fujita system has been reported to be second-order in ethylene pressure. ${ }^{4}$ Determining the order in [LAO] from its consumption over time would not be straightforward, given the competing catalyst decomposition and other complications; instead we examined the dependence of initial rate on [1-hexene] (measured by the amount of trimer formed after $1 \mathrm{~h}$, when LAO consumption, isomer formation and catalyst decomposition are all relatively small) for a series of 1hexene/hexane solutions, at both 25 and $0{ }^{\circ} \mathrm{C}$ (Fig. 3). The log-log plots show clear third-order dependence, as well as confirming the impression from Fig. 2 that the initial rate is very similar, at both temperatures.
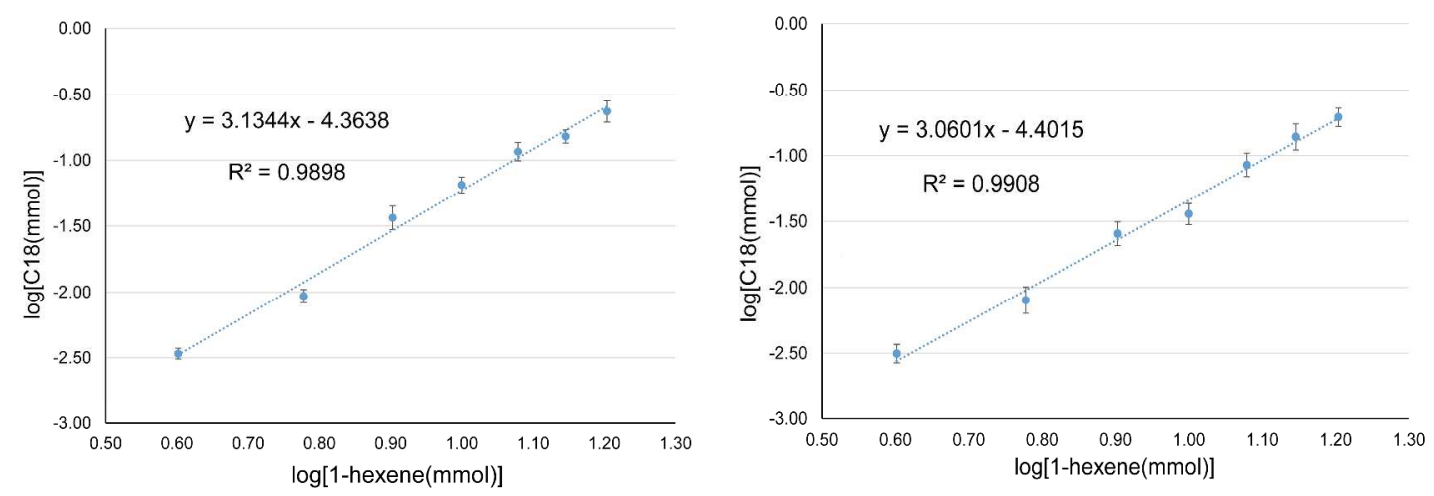

Figure 3. Log-log plot of amount of 1-hexene trimers formed after $1 \mathrm{~h}$ from solutions ranging from $25-100 \% 1$-hexene/hexane, at $25{ }^{\circ} \mathrm{C}$ (left) and $0^{\circ} \mathrm{C}$ (right).

Lastly, we examined whether the formation of internal olefin isomers might have any effect on the trimerization reaction. Trimerization does appear to be somewhat inhibited in the presence of internal olefins: solutions of 1:1 1-hexene/hexane, 1:1 (1- 
hexene $) /(17.5 \%$ trans-3-hexene $+82.5 \%$ hexane $)$, and 1:1 1-hexene/trans-3-hexene exhibit relative initial rates (over the first hour) in the ratio of 1:0.92:0.57. The unconjugated diene 1,4-hexadiene completely inhibits 1-hexene trimerization even at a low concentration relative to the LAO (1:9).

\section{DISCUSSION}

While a substantial number of selective ethylene trimerization catalysts have been reported, selective LAO trimerization is much less common; the supported Ti catalyst studied here, $\mathrm{s}(\mathrm{FI}) \mathrm{Ti}$, is one of only three examples. Catalytic performance appears to be mostly independent of chain length, with LAOs ranging from propylene to 1-decene giving comparable activities and selectivities, including a strong preference for a single regioisomer. The metallacycle-based mechanism established for ethylene trimerization presumably operates for LAOs as well, although that has not been explicitly demonstrated; the most likely sequence that would account for the regioselectivity is formation of the presumably less sterically crowded $\beta, \beta$ '-disubstituted metallacyclopentane followed by 1,2-insertion of the third LAO, although an alternate mechanism cannot be excluded (Scheme 2). Significant steric constraint is further suggested by the unreactivity of both internal and branched terminal olefins. It is difficult to compare the reactivity of LAOs with ethylene in any meaningfully quantitative sense, given the incommensurability of reaction conditions (especially substrate concentration, an important factor), but overall achievable productivity (limited by eventual catalyst decomposition as well as reaction rate) is around 1-2 orders of magnitude lower for LAOs. We have previously found that incorporation of a single LAO into an LAO-ethylene cotrimer has a rate constant around 70 times slower than that for ethylene. ${ }^{5}$

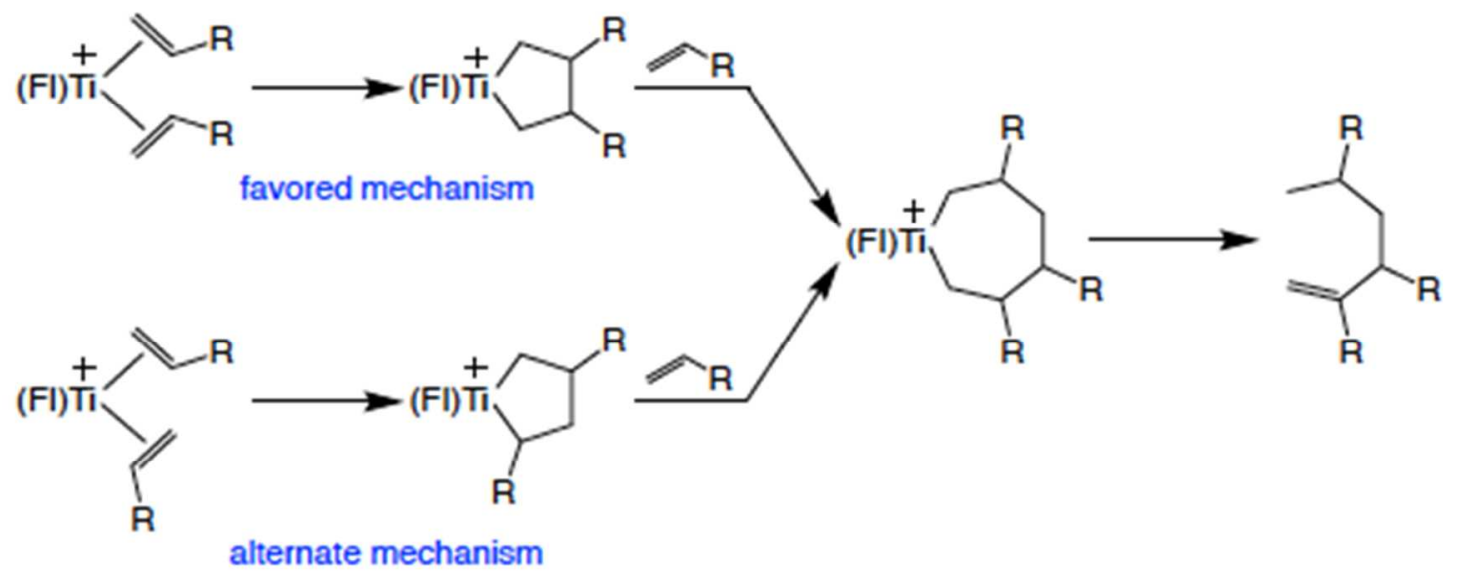

\section{Scheme 2. Favored and alternate mechanism for formation of major regioisomer}

Studies of ethylene trimerization by $(\mathrm{FI}) \mathrm{TiMe}_{3} / \mathrm{B}\left(\mathrm{C}_{6} \mathrm{~F}_{5}\right)_{3}$, a soluble analog of $\mathrm{s}(\mathrm{FI}) \mathrm{Ti}$, demonstrated that initiation (conversion of pre-catalyst $\left[(\mathrm{FI}) \mathrm{TiMe}_{2}\right]^{+}$to an active form) is 
slow relative to propagation, with catalyst decomposition roughly comparable in rate to initiation. That would suggest that for LAOs all three processes proceed on a similar time scale, making rigorous kinetic analysis very challenging. However, several semiquantitative observations, as outlined in the Results section above, include a couple of unexpected findings: third-order dependence on [LAO] and, especially, the virtually equal initial rates at 0 and $25^{\circ} \mathrm{C}$. We believe we can account for all the observations in terms of the mechanism shown in Scheme 3, with the following features.

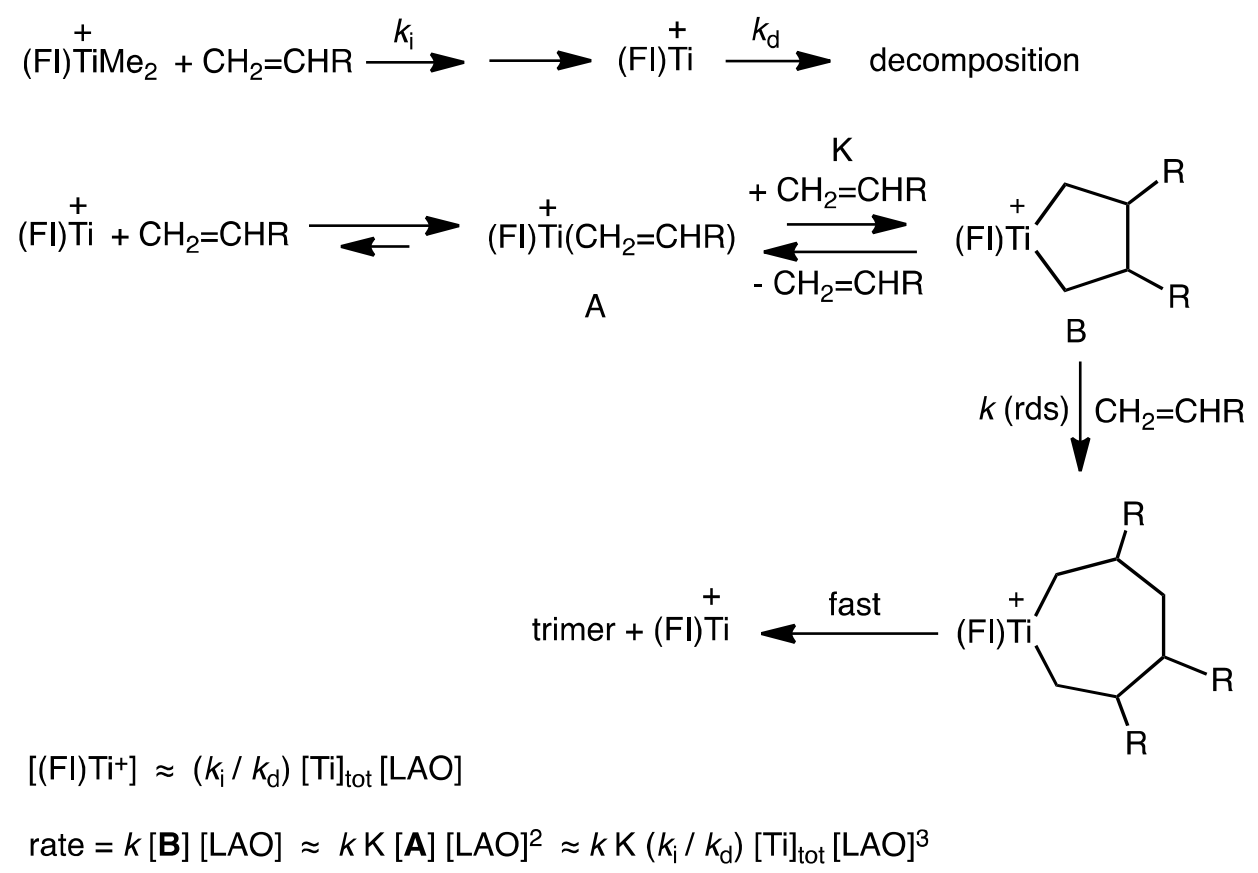

\section{Scheme 3. Proposed mechanism accounting for third-order kinetics}

First, two processes - catalyst decomposition and olefin isomerization - are significantly more temperature dependent than the others. Presumably all the steps, including initiation and propagation, are slower at 0 than $25^{\circ} \mathrm{C}$, but not proportionally so, or the behavior shown clearly in Fig. 2 could not be explained. This postulate alone can account for the substantial increase in overall productivity observed at the lower temperature: the catalyst lasts much longer, and less substrate is wasted by isomerization to inert internal olefins. Then, the strong reduction in rate of isomerization could explain the similarity in rates at the two temperatures, as generation of isomerized olefin would be expected to slow trimerization in two ways. Most importantly, an internal olefin was found to inhibit trimerization. Presumably this is a consequence of competition with the LAO for binding to a vacant site at one or more stages of the trimerization process initiation, metallacycle formation, etc. Also the internal olefin will act as a diluent, reducing the concentration of LAO as it proceeds; this might well be a significant effect as a result of the third-order kinetics. Thus the lower rate constant for propagation at 0 ${ }^{\circ} \mathrm{C}$ would be compensated for by the absence of any significant amount of isomers during the initial measurement period. 
How can we explain third-order [LAO] dependence? It is conceivable that it could arise from the participation of three molecules of LAO prior to the rate-determining step, but it seems far more likely that it reflects second-order dependence in propagation (as is the case for ethylene ${ }^{4}$ ) coupled with an LAO-dependent initiation step. For ethylene trimerization by $(\mathrm{FI}) \mathrm{TiMe}_{3} / \mathrm{B}\left(\mathrm{C}_{6} \mathrm{~F}_{5}\right)_{3}$, labeling studies indicate that initiation proceeds via insertion of ethylene into a Ti-Me bond of pre-catalyst $\left[(\mathrm{FI}) \mathrm{TiMe}_{2}\right]^{+}$followed by $\beta$ elimination and loss of methane. ${ }^{5}$ Presumably a similar process operates here. If we assume 1) steady-state behavior in active catalyst (FI) $\mathrm{Ti}^{+}$; and 2) olefin adduct $\mathbf{A}$ predominates among activated species during catalysis, we obtain the rate law shown in Scheme 3 (see SI for derivation), with propagation being second-order in [LAO] but overall third-order kinetics. Other scenarios are also possible.

While we still lack explanations for why these (FI)Ti-based catalysts (or any other particular structure) lead to selective trimerization as opposed to non-selective oligomerization, we hope that the mechanistic details generated in this work can eventually lead to a practical system for converting LAOs to more valuable products. Further work along these lines is ongoing.

\section{EXPERIMENTAL}

\section{$\underline{\text { General Considerations }}$}

All reactions unless otherwise stated were carried out under an inert dinitrogen atmosphere using standard glovebox, Schlenk line and high-vacuum line techniques. Toluene, hexane and pentane were obtained from a solvent purification system with activated alumina columns, degassed and left over $4 \AA$ molecular sieves for at least 16 hours prior to use. Methylaluminoxane (MAO) $(30 \% \mathrm{w} / \mathrm{v}$ in toluene) was received as a gift from Albermarle Corporation and stored at $-30{ }^{\circ} \mathrm{C}$ in a dinitrogen glovebox freezer. Silica (MS-3030) was obtained from PQ Corporation, heated at $300^{\circ} \mathrm{C}$ under vacuum for $5 \mathrm{~h}$ and then stored in a dinitrogen glovebox prior to use. s(FI)Ti was prepared according to literature procedures. ${ }^{7}$ 1-pentene, 1-hexene and 1-decene were purchased from SigmaAldrich Corporation, distilled, and scrubbed by passage through a column of $\mathrm{MAO} / \mathrm{SiO}_{2}$ prior to use. Propylene was purified by passage through a column containing activated molecular sieves and $\mathrm{MnO}$ dispersed on vermiculite prior to use. ${ }^{9}$ Propylene trimerizations were carried out in a glass reactor (miniclave steel ${ }^{\mathrm{TM}}$ type $1 / 300 \mathrm{~mL}, 10$ bar) obtained from Buchiglas-USA.

\section{$\underline{\text { Representative procedure for preparation of } \mathrm{MAO} / \mathrm{SiO}_{2}} \underline{\text { scrubber }}_{\underline{\mathrm{N}}}$}

In a dinitrogen-filled glovebox a $100 \mathrm{~mL}$ round bottom flask was charged with a Teflon stir bar, MS-3030 silica $(2.000 \mathrm{~g})$ and toluene $(25 \mathrm{~mL}) .3 .5 \mathrm{~mL}$ of 30 weight \% MAO was added dropwise to this stirring suspension, and stirring at ambient temperature was continued for 2 hours. After inserting a $180^{\circ}$ connector equipped with a Teflon valve the flask was taken out of the glovebox and attached to a vacuum line. The toluene was removed under vacuum to obtain a dry yellow powder (yield: $3.013 \mathrm{~g}$ ). 
$\underline{\text { Representative procedure for liquid LAO trimerization }}$

In a dinitrogen-filled glovebox a $20 \mathrm{~mL}$ scintillation vial was charged with a stir bar and $100 \mathrm{mg}$ of $\mathrm{s}(\mathrm{FI}) \mathrm{Ti}$. $2 \mathrm{~mL}$ of 1-decene was added and slurry stirred at ambient temperature for $16 \mathrm{~h}$. The reaction was then removed from the glovebox, and $1 \mathrm{~mL}$ of methanol and $5 \mathrm{~mL}$ of toluene were added to the solution. After filtration, the solution was analyzed using gas chromatography with adamantane as an internal standard.

Representative procedure for propylene trimerization

In a dinitrogen-filled glovebox a glass pressure reactor was charged with a stir bar, 312 $\mathrm{mg}$ of $\mathrm{s}(\mathrm{FI}) \mathrm{Ti}$ and $3 \mathrm{~mL}$ of pentane. The sealed reactor was taken out of the glovebox and placed in a cooling bath set to $5{ }^{\circ} \mathrm{C}$. The reactor was flushed 3 times with propylene at 4.4 bar to remove the inert gas. Then the pressure was increased to $\sim 7.8$ bar and propylene was allowed to condense. Approximately $50 \mathrm{~mL}$ of liquid propylene was added to the reactor prior to closing off the gas feed. The reaction was stirred for $47 \mathrm{~h}$ at an internal temperature of $5-10{ }^{\circ} \mathrm{C}$. Afterwards the propylene was allowed to evaporate by venting the reactor. To the residual oil in the vessel, $25 \mathrm{~mL}$ of methanol and $10 \mathrm{~mL}$ of acetone were added to precipitate a white polymeric residue $(1.1 \mathrm{~g}$, likely polypropylene + silica and catalyst residue) which was filtered off. A crude sample of the trimers was isolated by adding $40 \mathrm{~mL}$ of water to $10 \mathrm{~mL}$ of the methanolic filtrate with $2 \mathrm{~g}$ of ammonium chloride in a separatory funnel, which was shaken vigorously. A layer of oil was separated, dried with anhydrous magnesium sulfate, and analyzed using gas chromatography and NMR (see SI). GC analysis reveals 2,3,5-trimethyl-1-hexene $(87.9 \%$, three other nonenes: $6.2 \%, 4.4 \% .1 .1 \%$, total); total weight $=6.3 \mathrm{~g} ; \mathrm{mmols}$ propene converted to nonene $/ \mathrm{mmol} \mathrm{Ti}=43,000$.

\section{SUPPORTING INFORMATION}

Derivation of rate law; examples of product GC traces.

\section{AUTHOR INFORMATION}

E-mail addresses: J.A.L., jal@its.caltech.edu; J. E. B., bercaw@caltech.edu

\section{ACKNOWLEDGMENT}

We thank BP for funding, and BP scientists Glenn Sunley and Eric Doskocil for helpful discussions.

\section{REFERENCES}

(1) (a) Wright, M. E.; Harvey, B. G.; Quintana, R. L. (The United States of America as Represented by the Secretary of the Navy). US Patent 8,395,007, 2013. (b) Beech, J. H., 
Jr.; Owen, H.; Ramage, M. P.; Tabak, S. A. (Mobil Oil Corporation). US Patent 4,720,600, 1988.

(2) (a) Hamilton, L. A.; Seger, F. M. (Mobil Oil Corporation). US Patent 3,149,178, 1964. (b) Brennan, J. A. (Mobil Oil Corporation). US Patent 3,382,291, 1968.

(3) (a) Agapie, T. Coord. Chem. Rev. 2011, 255, 861-880. (b) McGuinness, D. S. Chem. Rev. 2011, 111, 2321-2341.

(4) (a) Köhn, R. D.; Haufe, M.; Kociok-Köhn, G.; Grimm, S.; Wasserscheid, P.; Keim, W. Angew. Chem. Int. Ed. 2000, 39, 4337-4339. (b) Wasserscheid, P.; Grimm, S.; Köhn, R. D.; Haufe, M. Adv. Synth. Catal. 2001, 343, 814-818. (c) Coxon, A. G. N.; Köhn, R. D. ACS Catal. 2016, 6, 3008-3016.

(5) Suzuki, Y.; Kinoshita, S.; Shibahara, A.; Ishii, S.; Kawamura, K.; Inoue, Y.; Fujita, T. Organometallics 2010, 29, 2394-2396.

(6) Sattler, A.; Labinger, J. A.; Bercaw, J. E. Organometallics 2013, 32, 6899-6902.

(7) Sattler, A.; Aluthge, D. C.; Winkler, J. R.; Labinger, J. A.; Bercaw, J. E. ACS Catal. 2016, 6, 19-22.

(8) Aluthge, D. C.; Sattler, A.; Al-Harthi, M. A.; Labinger, J. A.; Bercaw, J. E. ACS Catal., 2016, 6, 6581-4.

(9) Shriver, D.F.; Drezdzon, M. A.; The Manipulation of Air-Sensitive Compounds, 2nd ed.; Wiley-Interscience: New York, 1986; pp 78-80. 


\section{TOC Graphic}

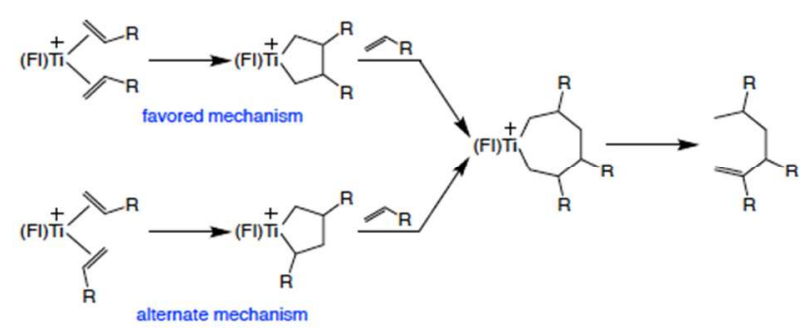

17

18

19

20

21

22

23

24

25

26

27

28

29

30

31

32

33

34

35

36

37

38

39

40

41

42

43

44

45

46

47

48

49

50

51

52

53

54

55

56

57

58

59

60 


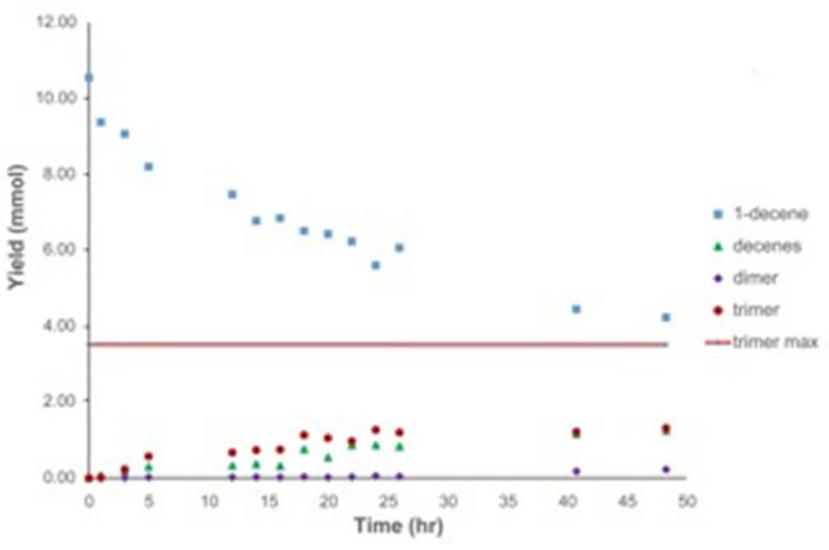

$112 \times 73 \mathrm{~mm}(72 \times 72 \mathrm{DPI})$ 


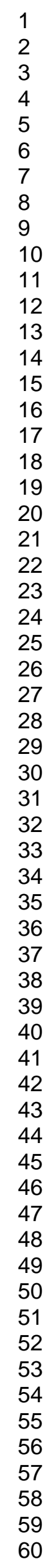

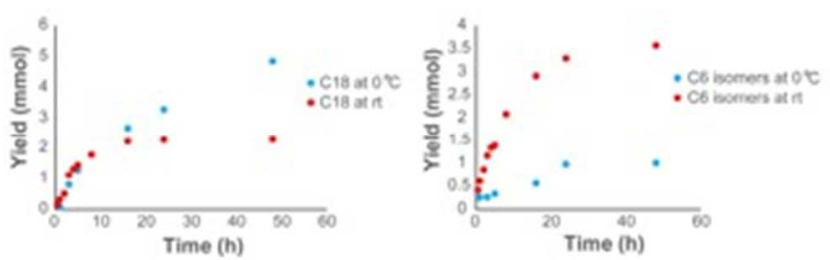

$112 \times 34 \mathrm{~mm}(72 \times 72 \mathrm{DPI})$ 


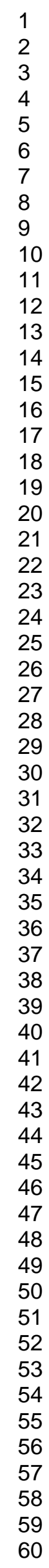

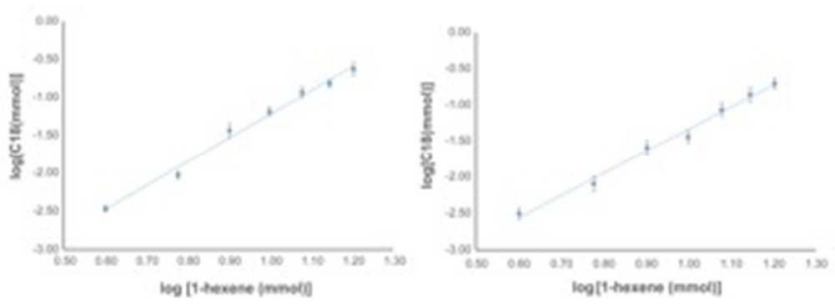

$112 \times 40 \mathrm{~mm}(72 \times 72 \mathrm{DPI})$ 